\title{
Myelodysplastic syndrome coexisting with acute lymphoblastic leukaemia
}

\author{
AN STARK, CS SCOTT, B BHATT, BE ROBERTS \\ From the Department of Haematology, Cookridge Hospital, Leeds
}

SUMMARY A 55 year old woman developed chronic myelomonocytic leukaemia (CMML) one year after she had been successfully treated for acute lymphoblastic leukaemia (ALL). When the ALL relapsed the CMML remitted only to return with further remission of the ALL. A consistent chromosomal abnormality, $\mathrm{t}(4 ; 11)$, was present during both CMML and ALL phases.

\section{Case report}

A 55 year old woman presented in February 1983 with left hypochondrial pain, which was diagnosed as splenic infarction. She was otherwise entirely well, and there were no relevant medical or family histories. Examination showed minimal cervical lymphadenopathy, together with hepatomegaly $(3 \mathrm{~cm})$ and splenomegaly $(4 \mathrm{~cm})$. Haemoglobin was $12.6 \mathrm{~g} / \mathrm{dl}$, platelets $67 \times 10^{9} / 1$, and white cells $4.8 \times 10^{9} / 1(50 \%$ neutrophils, $24 \%$ monocytes, $22 \%$ lymphocytes, $3 \%$ myelocytes, $1 \%$ blasts). Bone marrow aspirate showed $>90 \%$ blasts (mostly small), with a high nuclear:cytoplasmic ratio and indistinct nucleoli. The blasts were negative with Sudan black, peroxidase, and alpha-napthyl-acetate-esterase (ANAE) and reacted strongly with both antiterminal deoxynucleotidyl transferase anti-Tot and J5 (common acute lymphoblastic leukaemia antigen; CALLA) monoclonal antibody. Granulopoiesis, erythropoiesis, and megakaryo-poiesis were reduced but were of normal morphology. Serum lysozyme activity was $460 \mathrm{U} / \mathrm{ml}$ (normal range $200-500 \mathrm{U} / \mathrm{ml}$ ). Chromosomal analysis was not performed at this time. Common acute lymphoblastic leukaemia (C-ALL), was diagnosed and she received daunorubicin, vincristine, prednisolone, and L-asparaginase. Bone marrow aspirate at the end of week three showed complete remission.

She received further chemotherapy, but in April was noted to have an absolute monocytosis of $3.6 \times 10^{9} / 1$ (total white cells $8.5 \times 10^{9} / 1$ ). As she continued to have painful splenomegaly a further bone marrow aspiration was performed, which showed normal morphology in all three myeloid cell

Accepted for publication 6 February 1986 lines and confirmed continuing complete remission. 올 She received cranial irradiation uneventfully and was started on maintenance chemotherapy, but the splenomegaly persisted, as did the monocytosis, $\vec{\bullet}$ which was between $3-4 \times 10^{9} / 1$. A repeat bone marrow aspiration in early June showed normal morphology in all cell lines, though myelopoiesis was lefto shifted and $5 \%$ of nucleated cells were monocytes. Occasional ring sideroblasts were also seen on the Perls's iron stain but none of these features was $\frac{\varnothing}{\varnothing}$ thought to be particularly abnormal given the stage of $\cong$ her disease and treatment. More chemotherapy was $\overrightarrow{\overrightarrow{0}}$ given, but the spleen remained palpable. A bone mar- 3 row aspirate taken in December showed, apart from granulocytic hyperplasia with maturation arrest, nor-? mal erythropoiesis and megakaryopoiesis, and the peripheral blood monocyte count was $1.4 \times 10^{9} / 1^{\circ}$ (Fig. 1).

In February 1984 while maintenance chemotherapy was still being given, occasional agranular neutrophils were noted in the peripheral blood, witho the monocyte count ranging between 1.0-2.0 $\times 10^{9} / 1$. A bone marrow aspiration performed in early March음 was hypercellular with dysplastic erythropoiesis. Granulopoiesis was left shifted, with many agranularo and hypogranular forms present, and abnormaln megakaryocytes were also noted. Monocytes com- ్్ prised $10 \%$ of nucleated cells, and the serum $\sigma$ lysozyme activity was $1350 \mathrm{U} / \mathrm{ml}$. Chromosomal analysis of bone marrow cells, using methotrexate synchronisation and $\mathrm{G}$ banding, showed a $46 \mathrm{XX} \stackrel{\mathbb{\oplus}}{\oplus}$ $\mathrm{t}(4 ; 11),(\mathrm{q} 21 ; \mathrm{q} 23)$ karyotype in five of 23 metaphases examined. Chronic myelomonocytic leukaemia (CMML) was diagnosed.

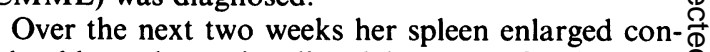
siderably and was irradiated because of pain. This $\varrho$ produced only temporary improvement, however, 
and by April the spleen was palpable $17 \mathrm{~cm}$ below the left costal margin. At the same time, blasts were noted in both the peripheral blood and bone marrow aspirate $(95 \%)$ with virtually absent erythropoiesis, myelopoiesis, and megakaryopoiesis. Immuno-

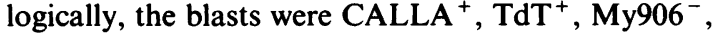
and $\mathrm{UCHM1}^{-}$, consistent with relapsed $\mathrm{C}-\mathrm{ALL}$. The serum lysozyme concentration had fallen to $610 \mathrm{U} / \mathrm{ml}$. Cytogenetic analysis of bone marrow aspirate continued to show a $t(4 ; 11)$ translocation plus a deletion of chromosomes 3,5, and 7. Reinduction chemotherapy was given with vincristine and prednisolone, with improvement both in symptoms and spleen size. As the peripheral blood blast count decreased, however, the monocyte count increased and the lysozyme activity rose to $2100 \mathrm{U} / \mathrm{ml}$. Bone marrow at the end of reinduction was consistent with CMML, with no evidence of ALL.

In July her spleen once again increased in size, and a bone marrow aspirate showed relapsed C-ALL with $45 \%$ blasts. Serum lysozyme activity was $1220 \mathrm{U} / \mathrm{ml}$ (Fig. 2). Chromosomal analysis of bone marrow aspirate again showed a $43 \times X \mathrm{t}(4 ; 11),(\mathrm{q} 21 ; \mathrm{q} 23),-3$, $-5,-7$ karyotype. Despite further salvage treatment she did not achieve complete remission and died in November 1984 with signs of spinal cord compression. Post mortem examination showed

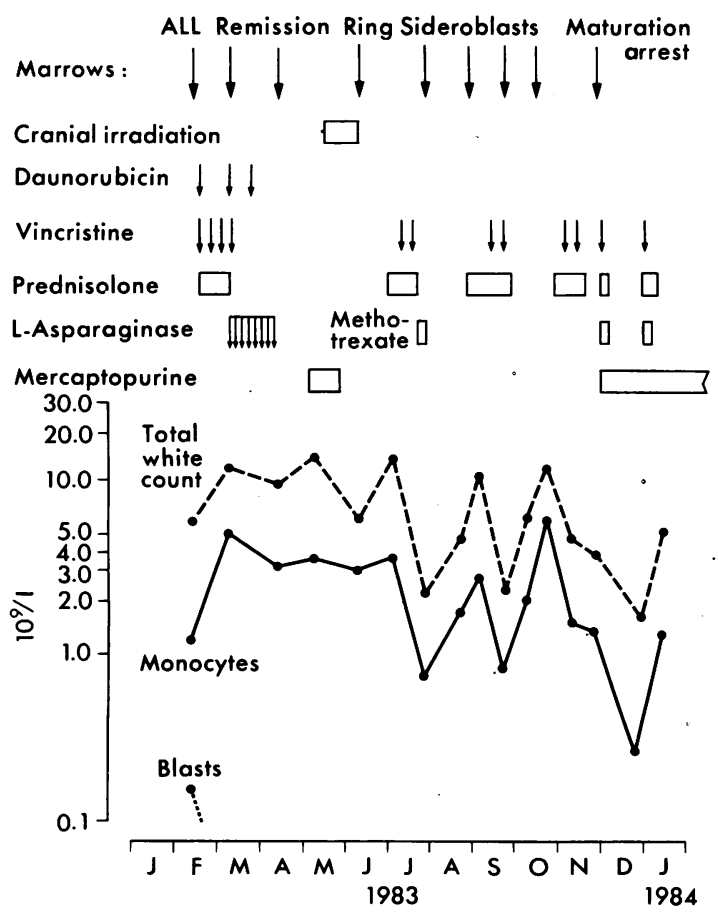

Fig. 1 Course of patient during initial induction and maintenance chemotherapy.

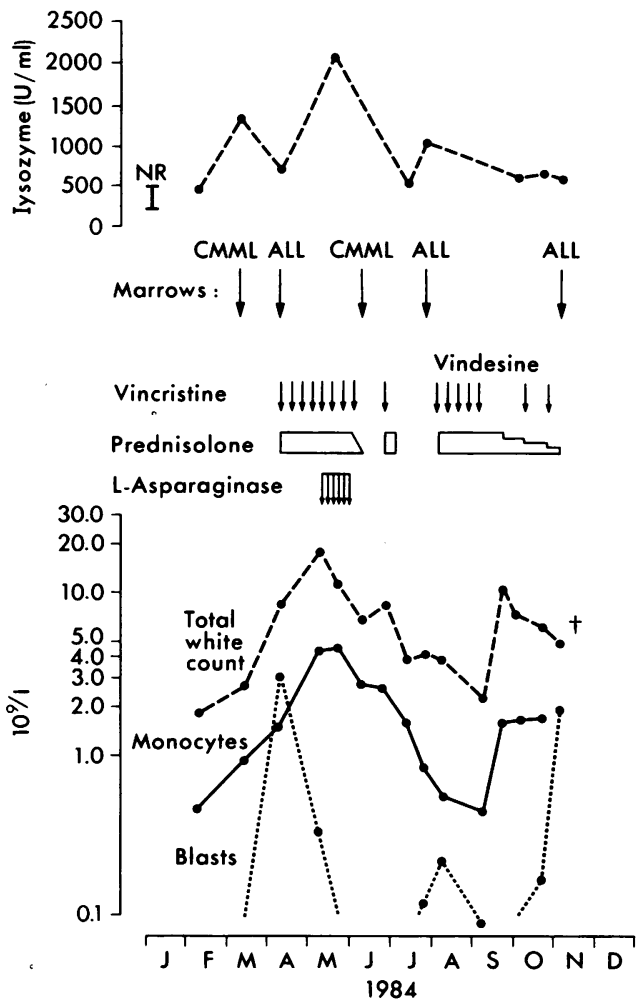

Fig. 2 Subsequent course of patient showing relation of relapsed $A L L$ and $C M M L$ and serum lysozyme activity.

infiltration of the spinal cord, brain, liver, spleen, and kidneys with malignant lymphoblasts.

\section{Discussion}

In this patient myelodysplastic syndrome, classified by $\mathrm{FAB}$ criteria as $\mathrm{CMML},{ }^{1}$ coexisted with both morphologically and immunologically confirmed CALL. When the ALL was in remission the CMML became dominant and the serum lysozyme activity increased while, in contrast, relapses of the ALL paralleled decreasing serum lysozyme activity. A consistent chromosomal abnormality was present both when the ALL was in relapse and also when it was in remission and CMML was present, suggesting that the two diseases were clonal and arose from a common malignant stem cell. In this respect it is interesting that a peripheral blood monocytosis was noted at first presentation of the ALL, even though the bone marrow did not show typical myelodysplastic changes until a year later. Chromosomal abnormalities affecting $\mathrm{t}(4 ; 11)$, (q21; q23), as in this case, are associated with ALL both with and without subsequent 
monocytic transformation. ${ }^{2-7}$ Most of these cases of ALL have, however, been of Null phenotype with only one previous case of $t(4 ; 11)$ in C-ALL. ${ }^{3}$ Furthermore, when monocytic transformation of these cases of ALL has occurred, it has been of the acute myelomonocytic or monocytic variety (M4, M5), ${ }^{24}$ which this patient did not have.

Myeloproliferative disease and apparent lymphoid malignancy are known to occur together in chronic myeloid leukaemia with lymphoid blast crisis (CMLLBC).$^{8}$ During LBC the CML is not often apparent, even though the blast cells usually still show the $\mathrm{Ph}^{1}$ chromosome. Successful treatment of LBC results in remission of the ALL, but not the CML, which invariably reappears. Our case would appear to be analogous to CML-LBC, though this situation has not, to our knowledge, previously been reported in myeloid dysplasia. It has been recently suggested that the translocation $t(4 ; 11)$ occurs in a pluripotential target cell, which could explain the mixed lymphoid and monocytic components often seen in these cases. ${ }^{6}$ As the c-oncogene c-ets is thought to lie in the region of the breakpoint in $t(4 ; 11),{ }^{6}$ it is tempting to speculate that it may participate in the malignant transformation, analogous to c-abl in CML.

\section{References}

${ }^{1}$ Bennett JM, Catovsky D, Daniel MT, et al. The FAB co-operative group. Proposals for the classification of the myelodysplastie syndromes. Br J Haematol 1982;51:189-99.

${ }^{2}$ Parkin J, Arthur DC, Abramson CS, et al. Acute leukaemia associ ated with the $t(4 ; 11)$ chromosome rearrangement: ultra structural and immunologic characteristics. Blood 1982;60\% 1321-31.

${ }^{3}$ Levin MD, Michael PM, Garson OM, Tiedmann K, Firkin FC Clinicopathological characteristics of acute lymphoblastic leu $\overline{\bar{S}}$ kaemia with the $4 ; 11$ chromosome translocation. Patholog. 1984;16:63-6.

${ }^{4}$ Nagasaka $M$, Maeda $S$, Maeda $H$, et al. Four cases of $t(4 ; 11)$ acuted leukaemia and its myelomonocytic nature in infants. Blood 1983;61:1174-81.

${ }^{5}$ Kokova M, Kowalczyk JR, Sandberg AA. Translocation of 4;1 L acute leukaemia: three case reports and review of the literature $\vec{\omega}$ Cancer Genet Cytogenet 1985;16:21-32.

${ }^{6}$ Secker-Walker LM, Stewart EL, Chan L, O'Callaghan U, Chesselा J. The $(4 ; 11)$ translocation in acute leukaemia of childhood: the importance of additional chromosomal aberations. Br J Hae matol 1985;61:101-11.

${ }^{7}$ Crist WM, Cleary ML, Grossi CE, et al. Acute leukaemias associ ated with the 4;11 chromosome translocation have rearrangeofo immunoglobulin heavy chain genes. Blood 1985;66:33-8.

${ }^{8}$ Janossy G, Greaves MF, Revesz T, et al. Blast crisis of chronic myeloid leukaemia II. Cell surface marker analysis of "lym=phoid" and myeloid cases. Br J Haematol 1976;34:179-92.

Request for reprints to: Dr CS Scott, Department of Haematology, Regional Radiotherapy Centre, Cookridge⿳亠口冋 Hospital, Leeds LS166QB, England. 